\title{
A Novel MYH9-RET Fusion Occurrence and EGFR T790M Loss as an Acquired Resistance Mechanism to Osimertinib in a Patient with Lung Adenocarcinoma: A Case Report
}

This article was published in the following Dove Press journal: OncoTargets and Therapy

Yanwei Sun'

Lina $\mathrm{Pei}^{2}$

Ningning Luo ${ }^{3}$

Dongsheng Chen ${ }^{3}$

Lingxin Meng'

'Department of Oncology, People's Hospital of Rizhao, Rizhao, People's Republic of China; ${ }^{2}$ Department of Pharmacy, People's Hospital of Rizhao, Rizhao, People's Republic of China; ${ }^{3}$ The State Key Laboratory of Translational Medicine and Innovative Drug Development, Jiangsu Simcere Diagnostics Co., Ltd, Nanjing, People's Republic of China
Correspondence: Lingxin Meng Department of Oncology, People's Hospital of Rizhao, Rizhao, People's Republic of China

Email menglingxinrz@126.com
Background: Osimertinib is a novel and irreversible epidermal growth factor receptor (EGFR)tyrosine kinase inhibitor (TKI) targeting EGFR sensitive mutations and EGFR exon20 p.T790M mutation, which demonstrated superior progression-free survival (PFS) and overall survival (OS). Case Presentation: We report a patient with lung adenocarcinoma harboring EGFR exon 19 deletion mutant treatment with icotinib. After 6 months, she developed $E G F R$ exon 20 p. T790M and then the patient received osimertinib treatment. A novel MYH9 (exon41)-RET (exon12) fusion and EGFR exon20 p.T790M loss were identified using plasma circulation tumor DNA (ctDNA) after osimertinib treatment, which led to rapid progression after osimertinib five months and suggested a potential resistance mechanism.

Conclusion: Our findings expanded the spectrum of RET arrangement types and provided the basis for this hypothesis: acquired RET rearrangement and EGFR exon20 p.T790M loss potentially serve an additional resistance mechanism to osimertinib in EGFR-mutated non-small-cell lung cancer (NSCLC).

Keywords: MYH9-RET fusion, EGFR exon20 p.T790M loss, lung adenocarcinoma, acquired resistance, osimertinib

\section{Introduction}

Approximately half of Asia-patients with NSCLC harbor EGFR mutation, and oral EGFR-TKIs have been used as one routine clinical therapeutic approach. ${ }^{1}$ Osimertinib is approved for both EGFR-TKI sensitive and EGFR exon20 p.T790M mutations in NSCLC patients. ${ }^{2,3}$ Previous studies described different resistance mechanisms to osimertinib, including EGFR tertiary mutations, like $C 797 S{ }^{4} K R A S$ mutations, and targetable gene fusions. ${ }^{5}$ In all NSCLC patients, $R E T$ fusion accounts for $1-2 \%$, involving various common fusion partners such as KIF5B and CCDC6. ${ }^{6}$ RET fusions have been proved that can mediate acquired resistance to EGFR-TKIs. ${ }^{7,8}$ Here, we reported a lung adenocarcinoma patient harboring a novel myosin heavy chain-9 (MYH9)-RET fusion, $E G F R$ exon19 deletion (exon19del) and EGFR exon20 p.T790M loss and exerted resistance to osimertinib.

\section{Case Presentation}

A non-smoking 48-year-old female was admitted to the hospital with intermittent cough and sputum for more than 4 months. Space occupying lesions were detected in 
the basal segment of the lower lobe of the left lung and intracranial site on admission examination. The immunohistochemistry staining results of pulmonary biopsy were CK5/ 6-positive, CK7-positive, thyroid transcription factor-1-positive, Naspin A-negative, P63-negative, P40-negative and Ki67 positive index $30 \%$ (Figure 1). The disease was diagnosed as advanced lung adenocarcinoma (poorly differentiated). To seek for precision therapy, next-generation sequencing (NGS) (14-gene panel) was performed in primary lung cancer lesion. EGFR exon19 p. E746_A750del and EGFR amplification were detected (Table 1). The patient was immediately treated with icotinib. However, after 6 months, the patient's condition deteriorated and the left lung tumor expanded. Then the detection of EGFR exon20 p.T790M was performed by ddPCR in plasma ctDNA and T790M positive was found. After that, the patient received osimertinib treatment and achieved a partial response with progression-free survival (PFS) of 5 months. Subsequently, the disease progressed with the left lung tumor enlarged.

Plasma ctDNA of patients after osimertinib treatment was tested by hybrid capture NGS method using 9-gene panel (Simceredx, CAP certified Laboratory), and EGFR exon19 p. E746_A750del, EGFR amplification as well as a novel MYH9 (exon41)-RET (exon12) fusion (Figure 2) were identified, without EGFR exon20 p.T790M. The findings of gene sequencing during
A

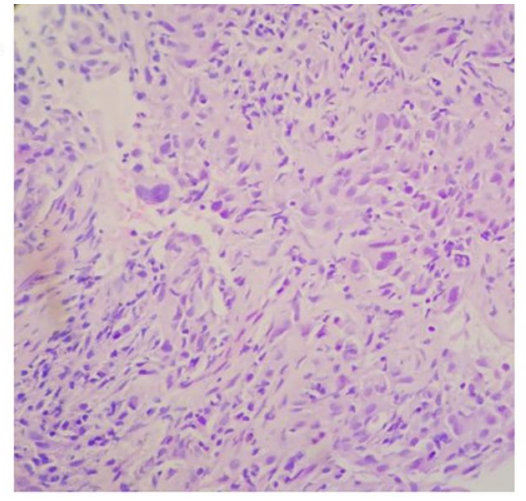

D

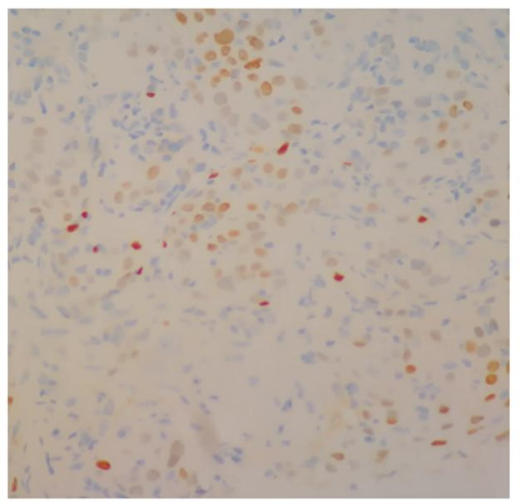

G

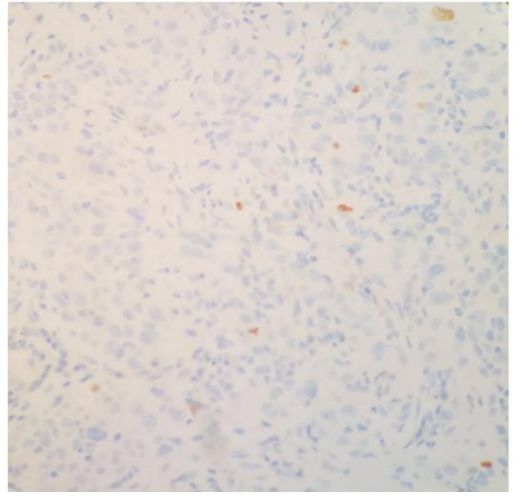

B

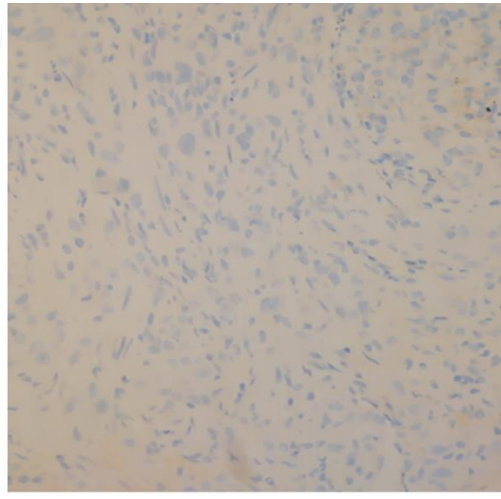

$\mathbf{E}$
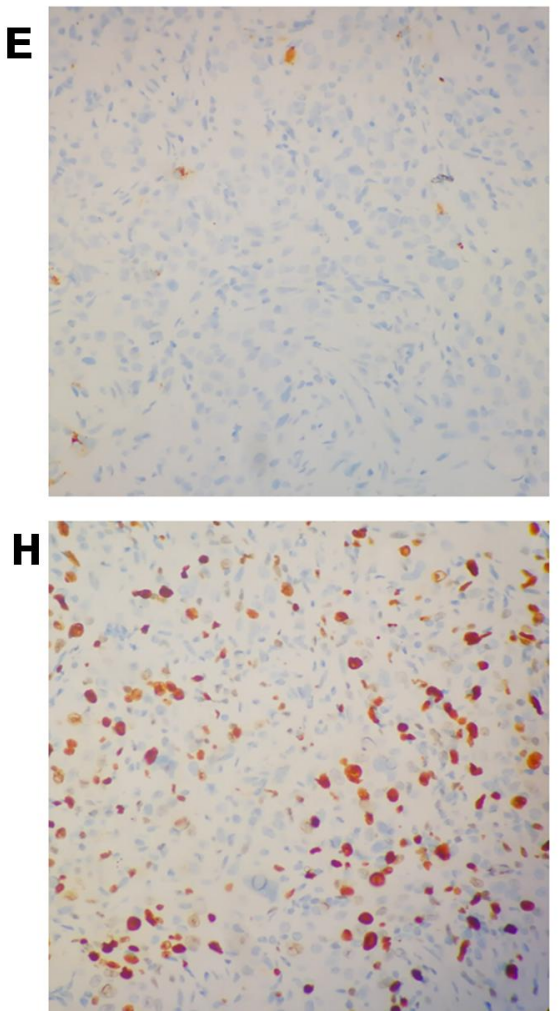
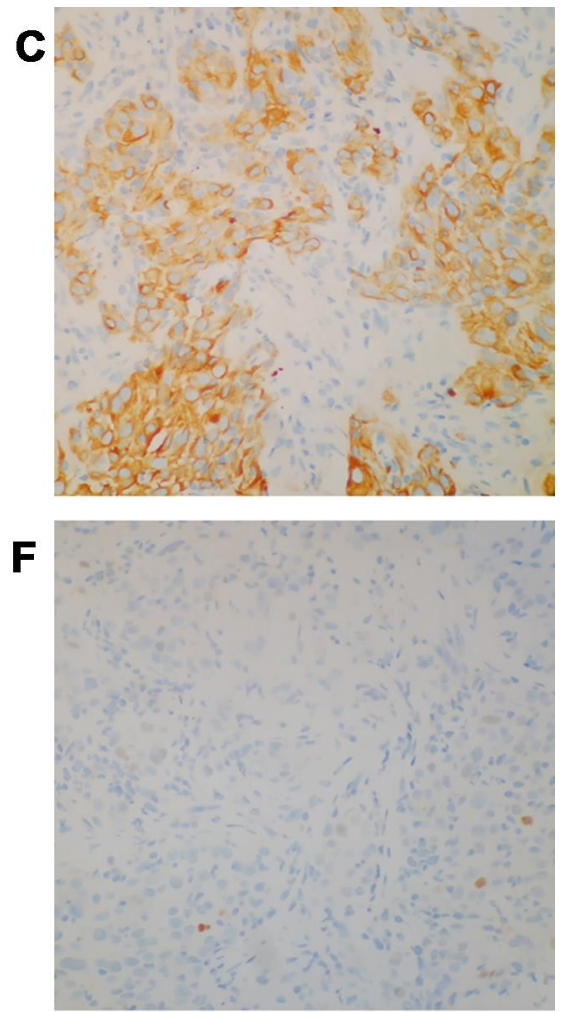

Figure I Histopathologic stains from the pulmonary biopsy. (A) hematoxylin and eosin. (B) CK5/6 (C) CK7. (D) thyroid transcription factor-I. (E) Naspin A. (F) P63. (G) P40. (H) Ki67. (×400). cytokeratin (CK). 
Table I Findings of Gene Sequencing During Treatment

\begin{tabular}{|c|c|c|c|c|c|}
\hline Time of Sampling & Method & Sample & Gene & Mutation Style & $\begin{array}{l}\text { Frequency (\%) or Copy } \\
\text { Number }\end{array}$ \\
\hline \multirow[t]{2}{*}{ Baseline } & \multirow[t]{2}{*}{$\begin{array}{l}\text { NGS (14-gene } \\
\text { panel) }\end{array}$} & \multirow[t]{2}{*}{$\begin{array}{l}\text { Puncture } \\
\text { tissue }\end{array}$} & EGFR & $\begin{array}{l}\text { Exon } 19 \\
\text { p. E746_A750del }\end{array}$ & $46.19 \%$ \\
\hline & & & EGFR & Amplification & 8 \\
\hline $\begin{array}{l}\text { After resistance to } \\
\text { icotinib }\end{array}$ & $\begin{array}{l}\text { Digital PCR } \\
\text { (T790M) }\end{array}$ & $\begin{array}{l}\text { Plasma } \\
\text { ctDNA }\end{array}$ & EGFR & $\begin{array}{l}\text { Exon } 20 \\
\text { p. T790M }\end{array}$ & $0.94 \%$ \\
\hline \multirow[t]{3}{*}{$\begin{array}{l}\text { After resistance to } \\
\text { osimertinib }\end{array}$} & \multirow[t]{3}{*}{$\begin{array}{l}\text { NGS (9-gene } \\
\text { panel) }\end{array}$} & \multirow[t]{3}{*}{$\begin{array}{l}\text { Plasma } \\
\text { ctDNA }\end{array}$} & EGFR & $\begin{array}{l}\text { Exon } 19 \\
\text { p. E746_A750del }\end{array}$ & $32.84 \%$ \\
\hline & & & EGFR & Amplification & 2.82 \\
\hline & & & $\begin{array}{l}\text { MYH9 (exon4I)-RET } \\
\text { (exon I2) }\end{array}$ & Fusion & $1.72 \%$ \\
\hline
\end{tabular}

treatment were given in Table 1 and time line of the treatments and the effects of different types of therapy were presented in Figure 3.

\section{Discussion}

In summary, this is the first case report that a novel MYH9$R E T$ fusion and EGFR exon20 p.T790M loss occurred in

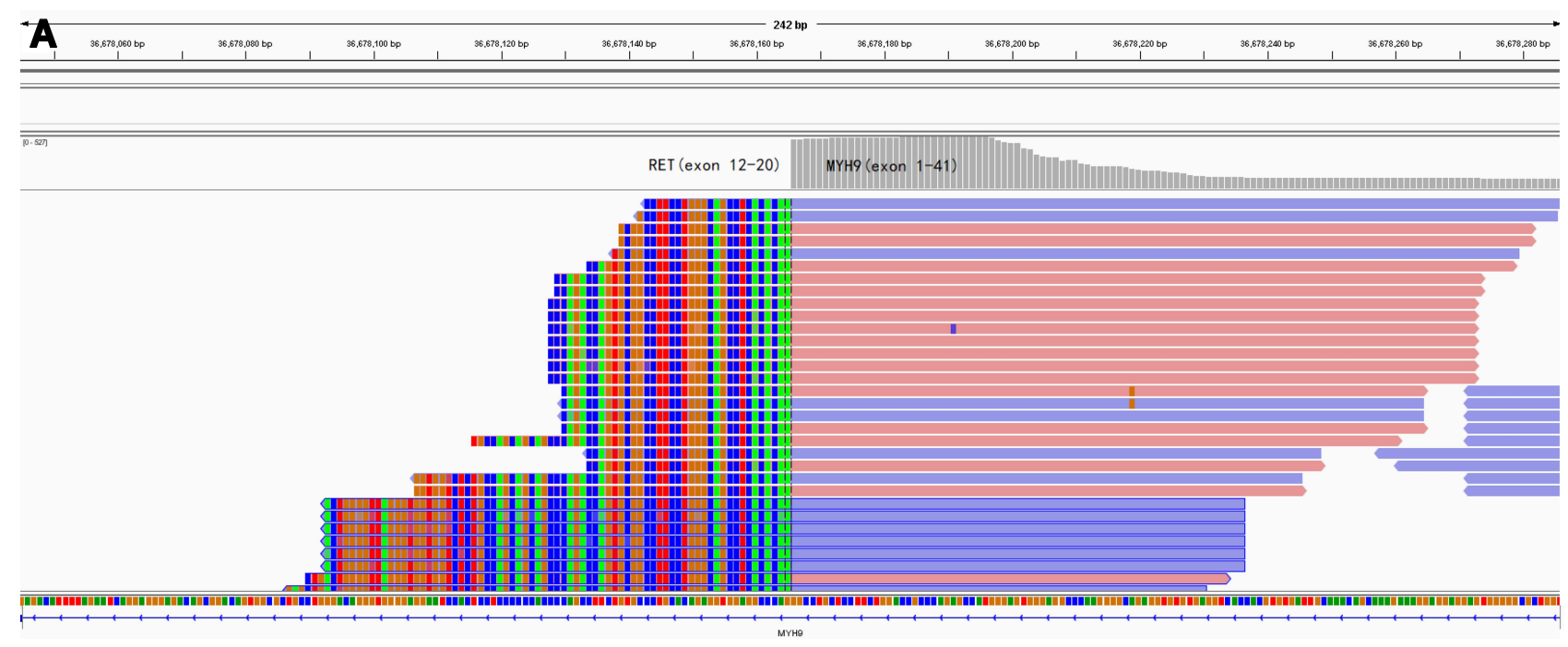

B

MYH9

RET

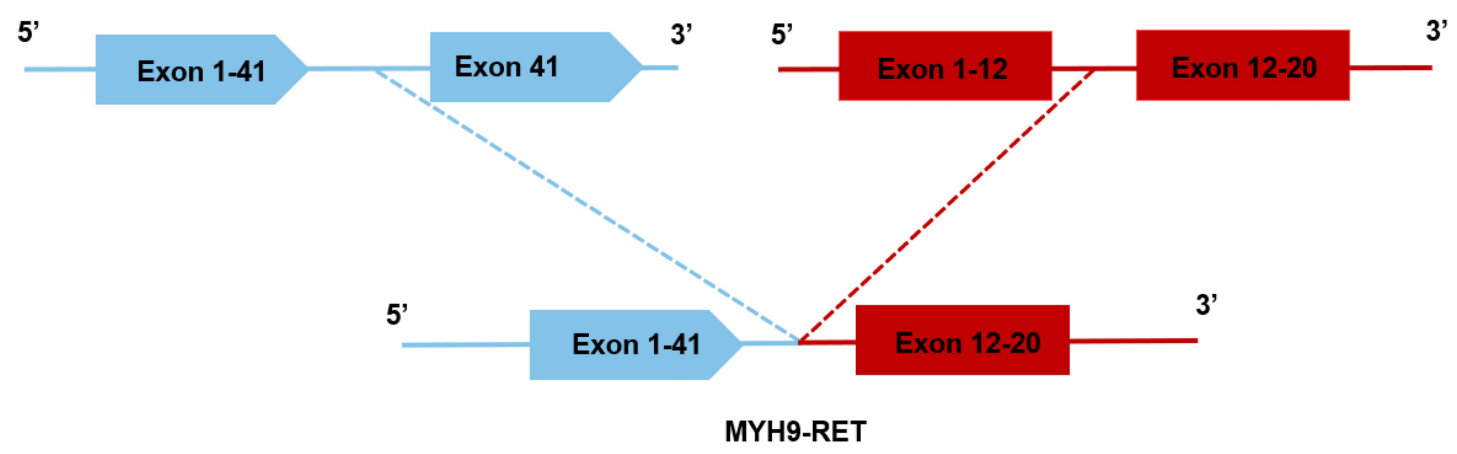

Figure 2 Next-generation sequencing findings of MYH9-RET fusion. (A) The Integrative Genomics Viewer snapshot of MYH9-RET. (B) Schematic representation of the MYH9-RET fusion protein domain structure. 


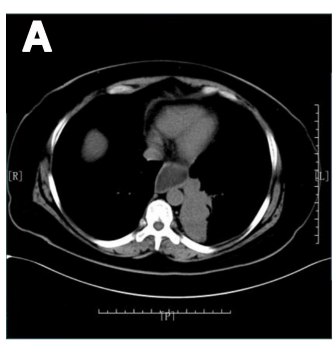

Baseline

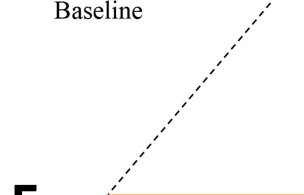

$\mathbf{F}$

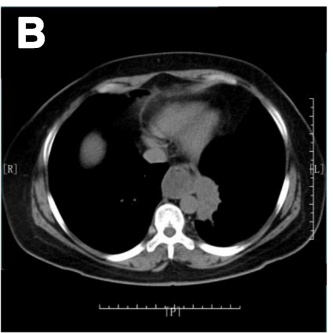

Icotinib $1 \mathrm{~m}$

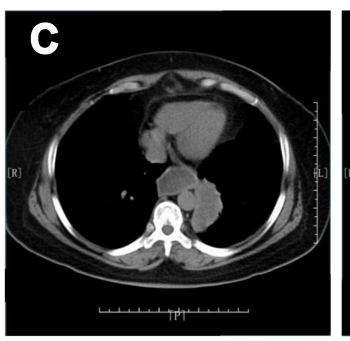

Icotinib $6 \mathrm{~m}$

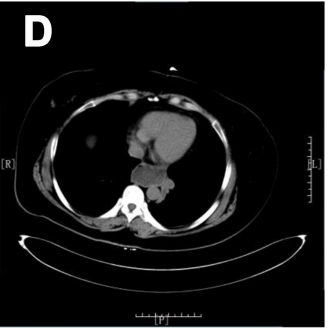

Osimertinib 2m

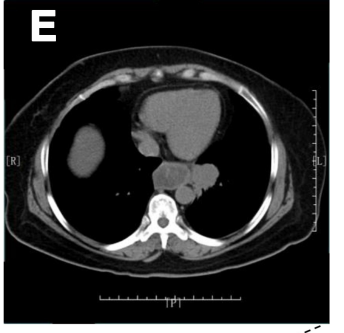

Osimertinib $5 \mathrm{~m}_{-}, \ldots$

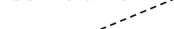

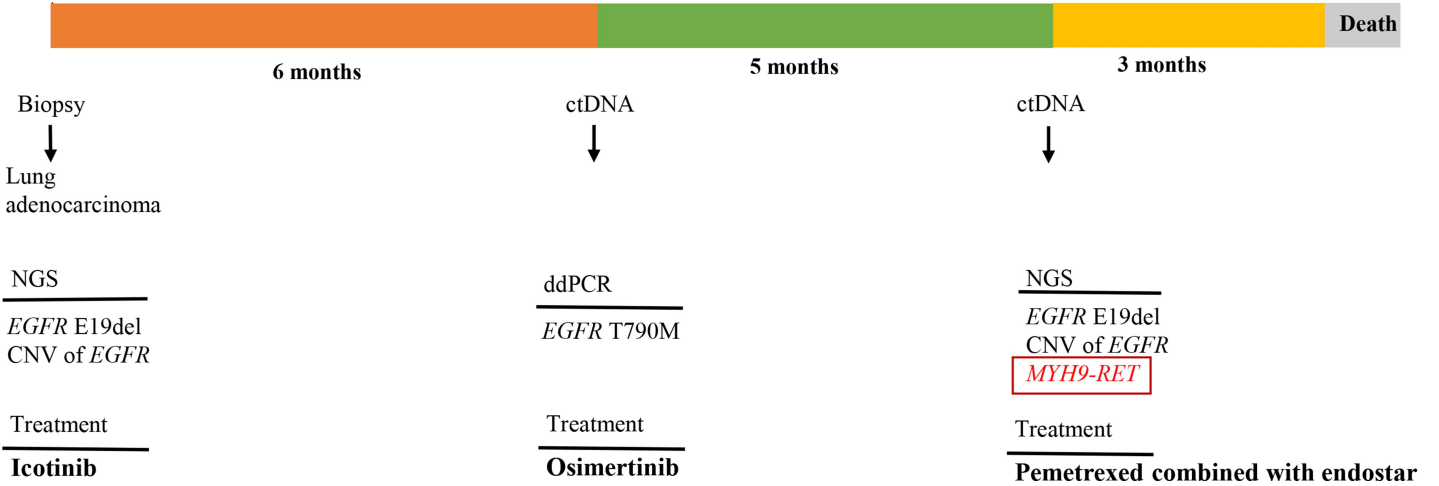

Figure 3 Computed tomography (CT) scan detecting and treatment course. (A-E) Chest CT scans showed the effects of different types of therapy of the patient's lung tumor. (F) Time line of the patient accepting treatments and duration of every treatment.

lung adenocarcinoma patient who acquired resistance to osimertinib treatment. MYH9-RET fusion retains the complete kinase domain of RET. Besides, the partner gene MYH9 contains a coiled-coil domain. MYH9-ALK fusion has been reported in 2003, which makes $M Y H 9$ a plausible partner for $R E T$ as well. ${ }^{9}$ This novel fusion is considered to promote ligand-independent dimerization and constitutive activation of RET. Previously reported that acquired RET fusions can overcome the osimertinib inhibitory effect by the activation of MAPK and PI3K signal pathway, which was sufficient to cause EGFR TKI resistance. ${ }^{10,11}$ The NSCLC patients harboring RET fusion may benefit from new highly selective RET inhibitors, such as BLU-667 and LOXO-292. Previously reported that $R E T$ fusion coexisted with $E G F R$ sensitive mutation in EGFR-mutated NSCLC patients who had progressed after first- or secondgeneration EGFR TKI treatment. $^{8}$

$E G F R$ exon 20 p.T790M loss has been reported in some osimertinib resistant cases. ${ }^{12-14}$ Genomic heterogeneity and clonal evolution including T790M-positive clones loss and selection of pre-existing resistance clones may contribute to the emergence of drug resistance. EGFR exon20 p.T790M was detected by NGS assay using
ctDNA rather than tissue sample after osimertinib resistance. However, it might be due to the low sensitivity of the ctDNA assay. This is one limitation of this case. But $R E T$ fusions as mechanisms of resistance to osimertinib have so far always been accompanied by T790M loss in EGFR-mutant Lung Cancers. ${ }^{7,10}$

Because of the patient achieving the partial response and the progression-free survival (PFS) of osimertinib treatment was merely 5 months, and no other resistance mechanisms identified, we considered that this novel MYH9-RET fusion acquired and T790M loss was an acquired resistance mechanism. One study has demonstrated that osimertinib and BLU-667 (one of RET inhibitors) might be a well tolerated and effective approach for EGFR-mutated NSCLC acquired RET fusion. ${ }^{7}$ However, the patient did not have a chance to receive this combination therapy and died 3 months later. Moreover, the patient did not undergo a biopsy at disease progression after osimertinib, so we did not confirm whether there was a potential histological transformation or not.

As a routine genetic testing approach, NGS is essential in identifying mutations that mediate primary or acquired resistance during treatment. Our case report expanded the 
spectrum of $R E T$ arrangement types and provided the basis for this hypothesis: acquired RET rearrangement and T790M loss can potentially serve an additional resistance mechanism to osimertinib in EGFR-mutated NSCLC.

\section{Ethics Approval and Consent for Publication}

A written informed consent was obtained from the patient's family for publication of the case details and any accompanying images and the research was approved by the Institutional Ethics Review Board of People's hospital of Rizhao.

\section{Acknowledgments}

The authors thank Mr. Chuang Qi, Mr. Hao Guo, Mr. Chao Song, Ms. Si Li and Ms. Xueyu Yang from Simceredx for the kindly assistance.

First author: Yanwei Sun; Department of oncology, People's hospital of Rizhao, Rizhao, China.

\section{Disclosure}

The authors have declared no conflicts of interest.

\section{References}

1. Shi Y, Au JSK, Thongprasert S, et al. A prospective, molecular epidemiology study of EGFR mutations in Asian patients with advanced non-small-cell lung cancer of adenocarcinoma histology (PIONEER). J Thorac Oncol. 2014;9:154-162. doi:10.1097/JTO.00 00000000000033.

2. Mok TS, Wu YL, Ahn MJ, et al. AURA3 investigators, osimertinib or platinum-pemetrexed in EGFR T790M-positive lung cancer. $N$ Engl $J$ Med. 2017;376:629-640. doi:10.1056/NEJMoa1612674.

3. Soria JC, Ohe Y, Vansteenkiste J, et al. Osimertinib in untreated EGFR -mutated advanced non-small-cell lung cancer. $N$ Engl $J$ Med. 2018;378:113-125. doi:10.1056/NEJMoa1713137.
4. Thress KS, Paweletz CP, Felip E, et al. Acquired EGFR C797S mutation mediates resistance to AZD9291 in non-small cell lung cancer harboring EGFR T790M. Nat Med. 2015;21:560-562. doi: $10.1038 / \mathrm{nm} .3854$.

5. Zhang YC, Zhou Q, Wu YL. Clinical management of third-generation EGFR inhibitor-resistant patients with advanced non-small cell lung cancer: current status and future perspectives. Cancer Lett. 2019;459:240-247. doi:10.1016/j.canlet.2019.05.044.

6. Li AY, McCusker MG, Russo A, et al. RET fusions in solid tumors. Cancer Treat Rev. 2019;81:101911. doi:10.1016/j.ctrv.2019.101911.

7. Piotrowska Z, Isozaki H, Lennerz JK, et al. Landscape of acquired resistance to osimertinib in EGFR -mutant NSCLC and clinical validation of combined EGFR and RET inhibition with osimertinib and BLU-667 for acquired RET fusion. Cancer Discov. 2018;8:1529-1539. doi:10.1158/2159-8290.CD-18-1022.

8. Klempner SJ, Bazhenova LA, Braiteh FS, et al. Emergence of RET rearrangement co-existing with activated EGFR mutation in EGFR mutated NSCLC patients who had progressed on first- or second-generation EGFR TKI. Lung Cancer. 2015;89:357-359. doi:10.1016/j.lungcan.2015.06.021.

9. Lamant L, Gascoyne RD, Duplantier MM, et al. Non-muscle myosin heavy chain (MYH9): a new partner fused to ALK in anaplastic large cell lymphoma. Genes Chromosomes Cancer. 2003;37:427-432. doi:10.1002/gcc.10232.

10. Offin M, Somwar R, Rekhtman N, et al. Acquired ALK and RET gene fusions as mechanisms of resistance to osimertinib in EGFR mutant lung cancers. JCO Precis Oncol. 2018;1-12. doi:10.1200/ PO.18.00126.

11. Yao Y, Zhang M, Liu X, et al. RET fusion in first/third-generation EGFR-TKIs resistance in advanced non-small cell lung cancer. $J$ Clin Oncol. 2019;37(15 suppl):e20634. doi:10.1200/JCO.2019.37.15 suppl. e20634

12. Zheng D, Hu M, Bai Y, et al. EGFR G796D mutation mediates resistance to osimertinib. Oncotarget. 2017;8:49671-49679. doi:10. 18632/oncotarget.17913.

13. Pisapia P, Rocco D, Pepe F, et al. EGFR exon 19 deletion switch and development of p.L792Q mutation as a new resistance mechanism to osimertinib: a case report and literature review. Transl Cancer Res. 2018;8:S64-S69. doi:10.21037/tcr.2018.09.13.

14. Oztan A, Fischer S, Schrock AB, et al. Emergence of EGFR G724S mutation in EGFR-mutant lung adenocarcinoma post progression on osimertinib. Lung Cancer. 2017;111:84-87. doi:10.1016/j.lungcan. 2017.07.002.
OncoTargets and Therapy

\section{Publish your work in this journal}

OncoTargets and Therapy is an international, peer-reviewed, open access journal focusing on the pathological basis of all cancers, potential targets for therapy and treatment protocols employed to improve the management of cancer patients. The journal also focuses on the impact of management programs and new therapeutic agents and protocols on patient perspectives such as quality of life, adherence and satisfaction. The manuscript management system is completely online and includes a very quick and fair peer-review system, which is all easy to use. Visit http://www.dovepress.com/ testimonials.php to read real quotes from published authors. 